Original Research Paper

\title{
India and the World after Covid-19: Climate Aspect
}

\author{
Avinash Sharma ${ }^{1}$, Nisha Adhikari' ${ }^{2}$ Jagdish Nath ${ }^{2}$ \\ ${ }^{1}$ Engineering College, Maharishi Markandeshwar (Deemed to be University) Mullana, \\ Ambala (Haryana), India. \\ ${ }^{2}$ Department of Computer Science, (Maharishi Markandeswar Deemed to be \\ University) Mullana, Ambala (Haryana), India.
}

\section{Article History}

Received:

27.07.2020

Revised:

27.08.2020

Accepted:

30.08 .2020

*Corresponding Author:

Avinash Sharma

Email:

asharma@mmumullana.org

This is an open access article, licensed under: $\mathrm{CC}-\mathrm{BY}-\mathrm{SA}$
Abstract: This research ponders over the climate aspect during the Covid 19 . The purpose of this is too aware and disseminate the outbreak of covid 19 cases hiking in a sky rocketing way. This study will focus on the contents of covid 19 where people are battling to overcome the hazard happening around vicinity brought by climate aspect. Its consist of information and analysis of different countries, metamorphosis of the nature with its pulchritude, tactic that need to be followed to overcome predicament, major affected tribe, initiative by various countries, climate aspect, impact at utmost level, drastic change within a smidge, crucial steps to curb COVID-19. This is also fruitful to know the behavior of nature during the COVID-19 climate change. The data were obtained through various authorized news channel and worldometers.

Keywords: Climate Aspect, Corona Virus, COVID-19. 


\section{Introduction}

"After a yore times nature seems to be metamorphosed its texture to the most beautiful version of "all this credibility goes to the pandemic covid-19 as this has created an intriguing ambience. Though this predicament has inflicting havoc across the globe but it has aid to curb the pollution. As no vaccines are yet developed lockdown has been taken as a measure to restrain the contagious corona virus .So, the industries, aviation, and other means of transportation has ceased resulting reduction of air pollution in the countries which is severely affected by the virus, such as China, Italy, and Spain. Carbon emission has been reduced as the policy of work from home is adherently followed due to which air quality in certain regions has improved in recent weeks as per the scientist.Climate change is one of the crucial reason for causing sneezing, fever, cold which directly links the symptoms of corona virus so as soon as the climate is changed it baffles the person and intimidates the person for being a suspect of covid 19. Instantaneous drop in pollution has underscored the extent to which it made us susceptible to the virus in the first place amid the burning of fossil fuel in vehicles, factories and power plants creates soot and other particles so small that they end up in almost every organ in the body, including the lungs. As novel Covid-19 is a respiratory malady causing pneumonia and result in severe, long-lasting lung damage where suspects are more likely to succumb if they live in regions with high levels of pollution as depicted in the early findings which has resonated with prepandemic research linking pollution to a long list of diseases. "Which seem to be impossible stand out to be possible in a way that never happened before "this pandemic act as a dispensation for curbing the pollution evacuating the venomous and pernicious ambience. The epidemic altered the soundscape in some of the world's noisiest cities promptly swapping engines and car horns with melody of bird chirping while on the other side it became cozy enough in many places to hear the melancholy blare of ambulance sirens. Although the reduced urban noise that of reductions in fossil fuel use and $\mathrm{CO} 2$ emissions, is something that climate action can target in handy way. Mega-cities in China and batterypower bikes have supplanted cars, buses and motorcycles demonstrate that this can be a perpetual aural state.

\section{Climate Aspect}

According to IQ Air, seven global cities that of Delhi, Sao Paulo and New York are observed to have a decline in fine particulate matter from 25 to 60 percent. On record till date the longest stretch of clean air has been achieved by Los Angeles.In recent years, we have generated around 500 tons of CO2 per \$1 million of the world's GDP as depicted by Steven Davis, Associate Professor in the Department of Earth System Science at the University of California.40 billion tons of $\mathrm{CO} 2$ were emitted per $\$ 88$ billions of the world's GDP as per the report of year 2019 [1] [2]. In case this association perseveres there is a decline of the world's GDP due to the forthcoming economic collapse that might generate a reduction in the global $\mathrm{CO} 2$ emissions in a similar proportion. Glancing an ambience of rarer planes in the air and cars on roads decline by $5 \%$ was observed in the first quarter of the year [3]. Halved the 2019 average in road transport activity was observed by the end of March when countrywide lockdowns commenced.Energy and climate adept Constantine Samaras states that "a pandemic is the worst possible way to reduce emissions" and that "technological, behavioural, and structural change is the best and only way to reduce emissions"-Tsinghua University's Zhu Liu clarifies that "only when we would reduce our emissions even more than this for longer would we be able to see the decline in concentrations in the atmosphere" [4] [5]. Amid coronavirus measures taken as lockdown the world has ceased its demand for fossil fuels and observed a decline of $10 \%$. A strenuous effort is carried out by the government for hiking the clean energy transition as a report by the London-based think tank conceives that the coronavirus pandemic may have pushed the fossil fuel industry into "terminal decline" as demand for oil and gas declines. It forecasts that an annual $2 \%$ drop in demand for fossil fuels could cause the future profits of oil, gas and coal companies to collapse from an estimated \$39tn to \$14tn [6] [7].

\subsection{Information and Analysis of Different Countries}

"Things went drastic within a smidge". A wall-lizard might not catch a moth as promptly as how the news of the turmoil got spread across the globe. A pint-sized $125 \mathrm{~nm}$ virus has ruled gigantic world in a ravage manner devastating the world economy, trade, industry, education system, climate, nature etc. Commencing on 30 January and hiking up in an unstoppable way till date it has colossal impact on the range of people that may be based on economic background that includes destitute, mediocre and affluent one or based on gender ie male and female. In a sky rocketing way per day 12,881 
nascent cases with 334 deaths reports amidst positive cases 366,946 including 160,384 active cases. Out of them, 194,325 got the nostrum and are migrated to safe site. Out of 6,249,668 samples tested, 12,237 deaths and $52.95 \%$ recovery rate was observed cum recoveries/deaths ratio $94.07 \%: 5.93 \%$ as stated in Indian Council of Medical Research. India has overtaken Russia to become country with third highest confirmed cases [8] [9] [10]. The country reports 698,183 corona virus cases till date amid 1989 positive cases more than Russia. A dire need for a vaccine against COVID-19 but it cannot be raced into actuality. Though ticklish in this pandemic vicinity but strenuous efforts are made throughout by the medico, scientist and other veteran but is futile for the ameliorating the cases .Of which 11 were in human trials there are 100 vaccine candidates in the world currently. Human clinical trials which was consented were by India inclusive of COVAXIN and ZyCov-D that is the limelight for the cessation novel coronavirus which has shown its qua to succumb 1.12 crore people globally with more than 5.3 lakh dead, as testified by the government. As per the ministry"Six Indian companies are working on a COVID-19 vaccine. Dr. Balram Bhargava in negotiation todoctors last week announced a vaccine for human trials is readiness to test in spite it appeared to be coercing them into getting a vaccine ready by August 15. As per the India Independence Day that falls on August 15, India will be able to set cage free from the corona virus and celebrate the worth day again. However, according to Bloomberg new energy finance more than half a trillion dollars worldwide are currently intended to be poured into high-carbon industries. Preliminary disclosures from the Bank of England's Covid Corporate Financing Facility indicate that billions of pounds of taxpayer support are intended to be funneled to fossil fuel companies. According toReclaim Finance the European Central Bank intends to allocate as much as €220bn (£193bn) to fossil fuel industries [11]. An assessment finds that a stimulus program that focuses on renewable energy and climate-friendly projects could create more than 100,000 direct jobs across Australia and estimates that every $\$ 1 \mathrm{~m}$ spent on renewable energy and exports creates 4.8 full-time jobs in renewable infrastructure while $\$ 1 \mathrm{~m}$ on fossil fuel projects would only create 1.7 full-time jobs-Secretary-general of the OECD club of rich called upon countries to "seize this opportunity [of the coronavirus recovery] to reform subsidies and use public funds in a way that best benefits people and the planet" [12]. During the pandemic many people have started recycling and bike sales upwelling.

\subsection{Metamorphosis of the nature with its pulchritude}

Nature has a lacuna without human. Even if its virtuous or wicked impact caused by human on nature they play a vivacious role. Within a short lapse of two months, condensed pollution has hoarded the lives of 4000 children under the age of 5 and 73000 adults over the age of 70 .Being the smallest particle it has shaken the foundation of gigantic world more in a devastating way adhering some positive impact that was relinquished by human. Now, human have understood the importance of protecting the nature through reduced pollution and putting some worth efforts such as plantation, avoiding deforestation, fossil fuel etc. The nature protection is in the hand of human but the violation that can be done by nature such as natural landslide, earthquake, landslide etc.is not in the hand of human .So, human and nature are the two wheels of a cart. Everybody is reluctant to the way covid 19 has curbed the pollution as it has dark cost to our mother earth, healthcare systems, and mental wellbeing of people around the world. Nevertheless, it has played an immense vital role for creating the ambience of verdant greenery, scenery beauty reflecting the comeliness of hills and rivers, nature being able to breathe freshly. The darkest side of this pandemic may be protean enough to ruin the world too i.eunder this pandemicstorms, flooding and droughts are the most immediately apparent sources of displacement and disruption. For example:Fiji was smashed by a category 5 tropical cyclone.The Gulf Coast of the USA is invigorating for a severe hurricane season meanwhile the state of Louisiana is spotted to be a countrywide perilous ambience for COVID-19 mortality [13] [14]. In South Africa, local authorities are in a cesspool of flood conceiving for the maintenance of social distancing as the policies are ticklish to be handy. Access to clean water amidst risk of acute food insecurity during June-September 2020 has been introduced by drought among throng of people in Zimbabwe.

\subsection{Tactic That Need To Be Followed to Overcome Predicament}

Foremost, there is a dire need to understand the fact by UN, COE, OSCE, INTERPOOL and other concerned authorities that protection should be hostage. The United Nation peace committee should set a firm determination for following the approaches inconflict resolution amidst America and Zhōngguó .On the other hand, to be the bridge across those differences and opposites, connecting to 
each other diverse peoples and countries with their heterogeneous interests, in mutually respectful, beneficial and reciprocal relations, imbued with the principles of human and harmonization that are on correspondence with the world war II is indispensable [15]. Catastrophe accentuates the significance of safeguarding rearrangement and sustenance intended for the utmost susceptible along with jobless, unoccupied and voluntary. Ultimately, this is about rational self-serving. This assemblies are alike to those who render the basic requisite like safety, health care and maintenance, food and many more. A rigorous focus on tackling inequality is desperately needed for giving rapport to the impoverished of countries through the global fund for social protection.

\subsection{Major Affected Tribe}

Structural bigotry and systemic biases has differentiated throng of people based on colour and the economically helpless to intensified menace in the critical time of both climate change and pandemics, a ticklish vicissitude that is unravel. Addressing the structural inequalities highlighted under climate change and the COVID-19 outbreak is following the tactic of inexpensive universal health coverage that resolves prejudiced access to both preventative and acute care. The current coinciding catastrophes standing unadorned pre-existing breaches in healthcare and social services that must be addressed. Achieving the World Health Organization's goal of global universal health coverage by 2030 is life-threatening to shrink health system vulnerability and to minimize long-term health impacts of climate-attributable events [16]. In some countries, policy steps taken during COVID-19 may lay the groundwork for permanent expansion of healthcare in this direction; already, Ireland has nationalized healthcare for the duration of the pandemic. Solutions like these that centre equity, justice and human rights will ensure resilience in both climate change adaptation and pandemic preparedness.

\subsection{Initiative by Various Countries}

On the climate tractability front, many countries comprising America that remain to discourse waning impacts through the highly inadequate frame of disaster response stating that there is still miniature eminence on pre-disaster readiness where the same agencies and resources that manage disasters are prescribed for building pliability to climate change on an ad hoc basis. The aid to cope with acute crises is vital through sufficient technical backing and funding and committing to automatic escalators. To trail conditions - like the COVID-19 crisis - that could lead to acute food crises. Programs like FEWS NET exemplify multinational cooperation that is informed by scientific projections, uses a systems approach to develop solutions and helps ensure ambitious action on a scale commensurate with global risks [17]. However, as the COVID-19 pandemic has demonstrated, technical core capacities alone are insufficient for preparedness and resilience: any climate adaptation framework must prioritize equitable outcomes and entrench good governance and accountability.

\subsection{Climate Aspect}

This pandemic forecast the commencement of New Year as the most scorching one on record. Hiking up of excess mortality and morbidity will be observed due to the extreme heat events as of those in Florida observed in the past few years. Ultimately, leading to dislocate control provisions, infirmaries and alternative services in the ambience of cities. Sizzling temperature concerned ailment amidst the destitute one with pre-existing health conditions, confined people. This predicament is jinx that has even touched to dislocates wildfires as an interconnection with the COVID-19 as wildfire prevention measures and firefighter training programs are ceased. An extreme bushfire period will probably exacerbate pandemic indisposition which will further trench healthcare and the budget. Taking an instance of water quality it is depicted that water in the canals are found to be lucid and experienced greater water flow in Venice. Shrinking of transportation usage and industrial activities has aid in the drop of carbon emissions that fell to seventeen percent leading annual carbon emission decline by $7 \%$ which was recorded after a yore time of World War II as a study in May 2020 is published [18].

\subsection{Impact at Utmost Level}

This pandemic forecast the commencement of New Year as the most scorching one on record. Hiking up of excess mortality and morbidity will be observed due to the extreme heat events as of those in Florida observed in the past few years. Ultimately, leading to disrupt power supplies, hospitals and emergency services, especially in cities. High risk of heat-related illness including destitute one those with pre-existing health conditions, confined people. This predicament is jinx that has even touched to 
dislocateswildfires as an interconnection with the COVID-19 as wildfire prevention measures and firefighter training programs are ceased. An extreme bushfire period will probably exacerbate pandemic indisposition which will further trench healthcare and the budget. Taking an instance of water quality it is depicted that water in the canals are found to be lucid and experienced greater water flow in Venice. Shrinking of transportation usage and industrial activities has aid in the drop of carbon emissions that fell to $17 \%$ leading annual carbon emission decline by $7 \%$ which was recorded after a yore time of World War II as a study in May 2020 is published [19]. Due to detriment of COVID-19 more than one billion youth are now no longer tangibly in school after the cessation of schools and universities across many prerogatives. The breach brought in academics by covid-19 is verily having mediocre and lasting penalties on the quality of education despite of the fact that strenuous efforts that is laudable enough by teachers, school administrations, local and national governments to cope with the unprecedented circumstances.As destitute one have the dearth of food and basic commodities how come the smartphones and internet connectivity be avail to them. Many vulnerable youth such as migrants or homeless youth are in precarious situations. They are the ones who can easily be overlooked if governments do not pay specific attention, as they tend to be already in a situation without even their minimum requirements being met on health, education, employment and well-being. In the 75 year history of the United Nations this is the most ferocious squall that has impaired many lives till date back from the yore times.

\subsection{Drastic Change within a Smidge}

Efficacious aspect of this pandemic is an aura of people who are intrigued towards yoga and meditation for mental and physical well being are spurring themselves amid other .On the other side the jaunty youths are utilizing the social media platform such as YouTube, instagram, facebook, twitter etc. for awareness amidst throng of people about covid 19 and the safety precautions to be taken including the tactic of washing hands, wearing mask in right way etc. The luddite one who were reluctant to new technology are lavishly enjoying their work from home through the virtual working life style. The destitute one are the one who are daily wage worker they are unable to get any job during this perilous ambience where they succumbed due to starvation [20]. This predicament has brought dearth of basic commodities and essentials such as mask and sanitizer as intimidated people are purchasing in bulk quantities including medicines, grocery items, fruits, vegetables etc without having a second thought of the others need as they need it direly. As per the observation in the hospitals non-covid patients (diabetes, heart diseases, and cancer) are dying due to lack of health facilities as major concern in the hospitals are given to the covid patients. As lockdown is the measure of covid-19 till vaccines are invented for which people are feeling secluded and wrecked resulting multitude of suicide, murder, domestic violence etc. reported in the crime book.

\subsection{Crucial Steps to Curb COVID-19}

Amidst the unravelling predicament administrations of the nation inclusive of health organizations, specialists who is proficient enough for prompt actions in order to confront COVID-19 plays an incredible role. At the same time we need to ponder over the predictable climate disasters to aid in curbing of beautiful lives. Amalgamation of urgent aid need and foremost assistant are principally expected to discover themselves located transversely manifold predicaments concurrently under exceptional stress. For an instance in the USA, the Federal Emergency Management Agency (FEMA) is now assigned with coordinating the nationwide COVID-19 response as well as any response to ongoing extreme weather and climate-related disasters. With the assistance of laws, policies and budgets both climate change adaptation and pandemic preparedness can be framed as part of countries' legal obligation to realize the right to health inclusive of universal health coverage and proactive climate resilience measures. In international human rights instruments alike the International Covenant on Economic, Social and Cultural Rights (1966), countries have onuses to respect, protect and fulfil the right to health, including taking steps to prevent epidemic disease [21]. There is collective acknowledgement that addressing climate change is a component of realizing the right to health. The Paris Agreement acknowledges that in taking action to address climate change, countries should consider, respect and promote their obligations on the right to health. Robust global cooperation and governance with a human rights- centred approach supported by appropriate legal and institutional frameworks is a prerequisite for successfully confronting these multi-dimensional, overlapping challenges with integrated solution. 


\section{Summary and Conclusion}

Covid 19 is "Wish forgotten, worth remembrance" as many people have devoted their time to family life rather than social life, perceive about the importance of being cautious ,trim and healthy eating habits, sit back and give time to the state of mind one is going through, pause for a second and ponder is being successful enough to run a happy life ,know the grievance of each of the family member what one is going through, be an adherent support system for maintaining patience amid the family members and most importantly be thankful for each day that we could live vivaciously to god, medico ,our national police officer, valiant soldiers and everyone who has let us breathe peacefully in this ticklish vicinity. Over that, have the perseverance in this pandemic about the "Positive Aspect of $\mathrm{C}$ in COVID-19" that is being calm, cooperative, creative, conscious and cognizant "about us rather than me. India and the world after COVID-19 will let gigantic growth of world to make the world a better place to live lavishly where one will be wary about health and sanitation, compassion for preserving the originality of nature preserving forest, wild animals etc.

\section{References}

[1] Q. Li, X. Guan, and P. Wu, "Early Transmission Dynamics in Wuhan, China, of Novel Coronavirus-Infected Pneumonia," The New England Journal Medicine, 2020. [Online]. Available: https://www.nejm.org/doi/full/10.1056/nejmoa2001316 [Accessed: April.25, 2020].

[2] C. Huang, Y. Wang, and X. Li, "Clinical features of patients infected with 2019 novel corona virus in Wuhan," China Journal Lancet. [Online] Available: https://pubmed.ncbi.nlm.nih. gov/31986264/ [Accessed: April. 25, 2020].

[3] L. Xu, Y. Mao, and G. Chen, "Risk factors for severe corona virus disease 2019 (COVID-19)." [Online]. Available: https://www.medrxiv.org/content/10.1101/2020.03.30.20047415v1.full.pdf [Accessed: Apri.25, 2020].

[4] C. Wu, and M. D. Xiaoyan, "Risk Factors Associated With Acute Respiratory Distress Syndrome and Death in Patients With Coronavirus Disease 2019 Pneumonia in Wuhan,China," JAMA Intern Med. Published. [Online]. Available: https://pubmed.ncbi.nlm.nih.gov/32167524/ [Accessed: March.13, 2020].

[5] D. S. Hui, T. A. Madani, and F. Ntoumi, "The continuing COVID-19 epidemic threat of novel coronaviruses to global health-The latest 2019 novel coronavirus outbreak in Wuhan, China," International Journals of Infectious Diseases: IJID: official publication of the International Society for Infectious Diseases, 2020.

[6] Anynomous, Virus Taxonomy, Classification and No-Menclature of Viruses: Ninth Report of the International Committee on Taxonomy of Viruses. San Diego, CA: Academic Press, 2012.

[7] K. Dhama, S. Khan, and R. Tiwari, "Coronavirus Disease 2019-COVID-19," Preprints, [Online]. Available: https://www.preprints.org/manuscript/202003.0001/v1 [Accessed: March 13, 2020].

[8] C. Geller, M. Varbanov, and E. Raphael, "Duval Human Coronaviruses: Insights into Environmental Resistance and Its Influence on the Development of New Antiseptic Strategies," Viruses, vol. 4, pp. 3044-3068, 2012.

[9] D. D. Richman, R.J Whitley and F.G Hayden, Clinical virology, 4th edition, Washington: ASM Press, 2016.

[10] P.C Woo, and Y. Huang, "Coronavirus Genomics and Bioinformatics Analysis," Viruses, vol. $2,2010$.

[11] H. L. Quigley, and J.T Mateos, The resilience of the Spanish health system against the COVID19 pandemic, Lancet Public Health. 2020. [Online]. Available: https://doi.org/10.1016/S24682667 (20)30060-8. [Accessed: April. 25, 2020].

[12] N. Kandel, S. Chungong, A. Omaar, and J. Xing, "Health security capacities in the context of COVID-19 outbreak: an analysis of International Health Regulations annual report data from 182 countries," Lancet, 2020. [Online]. Available: https://doi.org/10.1016/S0140-6736 (20)30553-5. [Accessed: April. 25, 2020].

[13] R. R. Ayebare, R. Flick, and S. Okware, "Adoption of COVID-19 triage strategies for lowincome settings," Lancet Respir Med, 2020. [Online]. Available: https://doi.org/10.1016/S22132600 (20)30114-4. [Accessed: April. 25, 2020]. 
[14] G. Kampf, D. Todt, S. Pfaender, and E. Steinmann, "Persistence of coronaviruses on inanimate surfaces and their inactivation with biocidal agents," Journal of Hospital Infection, vol. 104, pp. 246-251, 2020.

[15] A. A. Elfiky, "Anti-HCV, nucleotide inhibitors, repurposing against COVID-19," Life Sciences, 2020. [Online] Available: https://doi.org/10.1016/j.lfs.2020.117477. [Accessed: April. 25, 2020].

[16] C. M. Chu, V.C. Cheng, and I. F. Hung, "Role of lopinavir/ritonavir in the treatment of SARS: Initial virological and clinical findings," Thorax, vol. 59, no. 3, pp. 252-256, 2004.

[17] M. R. Loutfy, L. M Blatt, and K. A Siminovitch, "Interferon Alfacon-1 Plus Corticosteroids in Severe Acute Respiratory Syndrome: A Preliminary Study," J Am Med Assoc, vol. 290 no. 24, pp. 3222-3228, 2003.

[18] J.S.M Peiris, C. M. Chu, and V.C. Cheng, "Clinical Progression and Viral Load in A Community Outbreak of Coronavirus-Associated SARS Pneumonia: A Prospective Study," Lancet, vol. 361 pp. 1767-1772, 2003.

[19] I. S. Wang, B. Kang, and J. Ma, "A deep learning algorithm using CT images to screen for Corona Virus Disease (COVID-19)," MedRxiv, 2020. [Online]. Available: https://doi.org/ 10.1101/2020.02.14.20023028. [Accessed: April. 25, 2020]

[20] B. R. Beck, B.R., Shin, and B. Choi, "Predicting commercially available antiviral drugs that may act on the novel coronavirus (2019-nCoV), Wuhan, China through a drug-target interaction deep learning model,"BioRxiv, 2020. [Online]. Available: https://doi.org/10.1101 /2020.01. 31.929547. [Accessed: April. 25, 2020].

[21] J. Chen, L. Wu, and J. Zhang, "Deep learning-based model for detecting 2019 novel coronavirus pneumonia on 1 high-resolution computed tomography: a prospective study," MedRxiv, 2020. [Online]. Available: https://doi.org/10.1101/2020.02.25.20021568. [Accessed: April. 25, 2020]. 